\title{
Reaction of irbesartan with nitrous acid produces irbesartan oxime derivatives, rather than $N$-nitrosoirbesartan
}

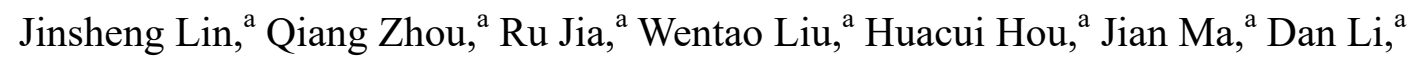

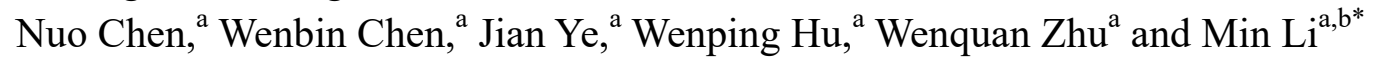

${ }^{a}$ Center of Excellence for Modern Analytical Technologies (CEMAT)

Huahai Pharmaceutical Co., Ltd, Xunqiao, Linhai, Zhejiang, P.R. China 317024

${ }^{b}$ Huahai US, Inc. 700 Atrium Drive, Somerset, NJ 08873, USA

KEYWORDS: Irbesartan, nitrous acid, $N$-nitrosoirbesartan, LC-MS, NMR, structural elucidation

\section{ABSTRACT}

In October 2021, a number of batches of irbesartan and irbesartan hydrochlorothiazide finished products were recalled from the US market, due to the presence of unacceptable level of the probably carcinogenic nitrosamine $N$-nitrosoirbesartan. Nevertheless, there is no revealing of the exact structure of this hypothetical $N$-nitrosoirbesartan. In the current study, we performed a set of 10 reactions of irbesartan with nitrous acid under various conditions and found no trace of this hypothetical $N$-nitrosoirbesartan by a sensitive and accurate LC-MS method with limit of detection (LOD) of $30 \mathrm{ppb}$. With the use of LC-PDA/UV-high resolution $\mathrm{MS}^{\mathrm{n}}$ as well as 1D/2D NMR, the reaction products formed are found to be the two isomeric oxime derivatives of irbesartan, with the $Z$-isomer as the predominant product. Furthermore, no trace of this hypothetical $\mathrm{N}$-nitrosoirbesartan can be detected in representative commercial batches of irbesartan. Despite of the fact that in silico evaluation suggests that the two irbesartan oximes may be controlled as regular 
impurities, analysis of representative irbesartan commercial batches by the LC-MS method indicates that the oximes are not detected (LOD: $30 \mathrm{ppb}$ ).

\section{INTRODUCTION}

Irbesartan (Fig. 1), with its IUPAC name as 2-butyl-3-[[4-[2-(2H-tetrazol-5-yl)phenyl]phenyl]methyl]-1,3-diazaspiro[4.4]non-1-en-4-one, is a potent and selective angiotensin II subtype 1 receptor antagonist or blocker. Hence it belongs to the family of ARB (angiotensin receptor blocker) drugs, which are also known as sartan drugs. Irbesartan is clinically indicated for treatment of hypertension, including patients with type 2 diabetes mellitus and nephropathy. ${ }^{1}$ In mid-2018, $N$-nitrosodimethylamine (NDMA), an $N$-nitrosoamine impurity with carcinogenicity to rats, ${ }^{2}$ was found in another sartan drug, valsartan, which caused voluntary recalls of impacted valsartan products from the market. ${ }^{3}$ Since that time, NDMA, as well as other $N$-nitrosoamine impurities, have been found in other categories of drugs beyond sartans, e.g., ranitidine and metformin drug products. ${ }^{4}$ Regulatory agencies have since issued various guidance and regulatory documents to mitigate and reduce the potential risk associated with $\mathrm{N}$-nitrosoamine impurities, ${ }^{5}$ which are among the "cohort of concert" genotoxic impurities as defined in ICH M7. ${ }^{6}$

Most recently in October 2021, a number of batches of irbesartan and irbesartan hydrochlorothiazide finished products were recalled from the US market, due to the potential presence of unacceptable level of $N$-nitrosoirbesartan. ${ }^{7}$ Nevertheless, there is no revealing of the exact structure of this hypothetical $N$-nitrosoirbesartan. Search of 
literature did not show any structure corresponding to this hypothetical $N$-nitrosoirbesartan. On the other hand, a few websites for companies engaged in supplying pharmaceutical impurities listed the structure of " $N$-nitrosoirbesartan" as the one with the nitroso group attached to the tetrazole moiety of irbesartan (Fig. 1); nevertheless, no detailed structure characterization can be provided. ${ }^{8}$ Under this background, we set out to determine whether the hypothetical $N$-nitrosoirbesartan can be produced by reaction between irbesartan and nitrous acid (formed in situ between a nitrite salt and acid) and if yes, what its exact structure would be.

Through a systematic study in which various reaction conditions have been tried, we did isolate two products from the reaction of irbesartan and nitrous acid, with their molecular formulas consistent with that of the hypothetical $N$-nitrosoirbesartan. Nevertheless, the two products are not $N$-nitrosoirbesartan, but rather are irbesartan oximes (Fig. 1), which are isobaric to the hypothetical $N$-nitrosoirbesartan. In this paper, we describe the details of the experimental design, isolation of the two products, their structural elucidation by LC-high resolution $\operatorname{MS}^{\mathrm{n}}(\mathrm{n}=1,2)$, and 1D and 2D NMR. We also performed genotoxic risk assessment using the software CASE Ultra, developed by MultiCASE, and found that they can be classified as Class 5 impurities, indicating that they may be controlled as regular impurities.

\section{RESULTS AND DISCUSSION}

\subsection{Original goal of the study for the reaction of irbesartan with nitrous acid}

The news of the irbesartan finished product recall due to the potential presence of 
$N$-nitrosoirbesartan ${ }^{7}$ prompted us to look into the possibility of whether this $N$-nitrosoirbesartan could be present in our irbesartan product, despite its being a remote possibility based on the risk assessment of our process chemistry.

\subsection{Product distribution in the reaction of irbesartan with nitrous acid}

In the first reaction of irbesartan with nitrous acid (generated in situ from sodium nitrite and $\mathrm{HCl}), 3.00 \mathrm{~g}$ irbesartan $(7.00 \mathrm{mmol})$ was dissolved in $10 \mathrm{~mL} \mathrm{NMP}$. To this solution was added $0.300 \mathrm{~g} \mathrm{NaNO}_{2}(4.35 \mathrm{mmol})$ followed by addition of $2.0 \mathrm{~mL}$ concentrated hydrochloric acid $(24 \mathrm{mmol})$ and $1.0 \mathrm{~mL}$ water. The reaction solution was allowed to stir at $40 \pm 2^{\circ} \mathrm{C}$ for $18 \mathrm{~h}$. LC-UV/PDA-high resolution $\mathrm{MS}^{\mathrm{n}}(\mathrm{n}=1,2)$ analysis of the reaction solution indicated that two product peaks eluted at 22.6 and $27.0 \mathrm{~min}$ (Fig. 2), with their peak area percentages at $0.81 \%$ and $42.85 \%$, respectively. It was found that the UV spectra of the $22.6 \mathrm{~min}$ and $27.0 \mathrm{~min}$ products are quite similar to that of irbesartan with three UV absorption peaks near 225, 255 and $280 \mathrm{~nm}$, indicating that these three compounds have similar chromophores (Fig. S1; Supporting information).

\subsection{High resolution mass spectrometric analysis of the two products formed in the reaction of irbesartan with nitrous acid}

The accurate MS spectra of the minor 22.6 min product and major $27.0 \mathrm{~min}$ product displayed their protonated $\mathrm{m} / \mathrm{z}$ values at 458.2322 and 458.2326 under ESI positive mode (Fig. S2), respectively, both matching a formula of $\mathrm{C}_{25} \mathrm{H}_{27} \mathrm{~N}_{7} \mathrm{O}_{2}$ within an experimental error of $10 \mathrm{ppm}$. The results indicate that the minor $22.6 \mathrm{~min}$ and major 27.0 min products are isomeric toward each other. By comparing with the 
formula of irbesartan, $\mathrm{C}_{25} \mathrm{H}_{28} \mathrm{~N}_{6} \mathrm{O}$, the $22.6 \mathrm{~min}$ and $27.0 \mathrm{~min}$ products have one additional NO component and less one hydrogen atom. Hence, the formula of both products from the reaction of irbesartan with nitrous acid would be consistent with that of $N$-nitrosoirbesartan. In order to further prove the identities of both products, MS/MS fragmentation experiments were performed on irbesartan and its two products.

The MS/MS spectra (Fig. 3) of both protonated $22.6 \mathrm{~min}$ and 27.0 min products $(\mathrm{m} / z$ 458) and irbesartan $(\mathrm{m} / z$ 429) did not show many fragment ions but exhibited three common fragment ions at $\mathrm{m} / \mathrm{z} 180, \mathrm{~m} / \mathrm{z} 207$ and $\mathrm{m} / \mathrm{z} 235$ under the collision energy of $30 \mathrm{eV}$. These three ions are the specific fragments originating from the biphenyltetrazole moiety, and their occurrence is indicative of the presence of an unmodified tetrazole moiety. Hence, the presence of these three common fragment ions suggests that the $22.6 \mathrm{~min}$ and $27.0 \mathrm{~min}$ products are very likely to have the same core structure of biphenyltetrazole as irbesartan. In other words, it does not seem to be likely that the two products are $N$-nitrosoirbesartan.

In order to determine the exact structures of the $22.6 \mathrm{~min}$ and $27.0 \mathrm{~min}$ products, it became necessary to isolate the two degradants for 1D and 2D NMR structural elucidation.

\subsection{Structural elucidation of the $22.6 \mathrm{~min}$ and $27.0 \mathrm{~min}$ products by $1 \mathrm{D}$ and $2 \mathrm{D}$} NMR

The two degradants were isolated by preparative reversed phase HPLC, the details of which are described in the experimental section. All the ${ }^{1} \mathrm{H}$ NMR (Fig. 4) 
and ${ }^{13} \mathrm{C}$ NMR (Fig. 5) data of irbesartan, $22.6 \mathrm{~min}$ and $27.0 \mathrm{~min}$ products are summarized in Table 1 . The ${ }^{1} \mathrm{H}$ and ${ }^{13} \mathrm{C}$ chemical shifts of irbesartan presented are consistent with those reported by Bernhart et. al. ${ }^{9}$ Like irbesartan, the ${ }^{13} \mathrm{C}$ NMR spectra of $22.6 \mathrm{~min}$ and $27.0 \mathrm{~min}$ products both displayed 21 carbon signals, the chemical shifts of which are quite similar to those of irbesartan, except for C-22 and, to a less degree, $\mathrm{C}-17$. The $\mathrm{C}-22$ signals of the $22.6 \mathrm{~min}$ and $27.0 \mathrm{~min}$ products are at 152.1 and $148.5 \mathrm{ppm}$, respectively, which are both quaternary carbons. On the other hand, the C-22 signal of irbesartan is a methylene carbon $\left(-\mathrm{CH}_{2}-\right)$ with a chemical shift at $27.5 \mathrm{ppm}$. These results suggest that the C-22 position of irbesartan was modified during its reaction with nitrous acid. Considering the fact that nitrous acid is an electrophilic reagent by virtue of its capability of donating ${ }^{+} \mathrm{NO}$ ion and that the C-22 position of irbesartan is nucleophilic in its enamine form, ${ }^{10}$ the initial reaction between irbesartan and nitrous acid would be for the C-22 position to launch a nucleophilic attack on the NO moiety of nitrous acid to form the carbon-based NO-substituted irbesartan intermediate, which would then rearrange into the two isomeric irbesartan oxime derivatives, i.e., the $22.6 \mathrm{~min}$ and $27.0 \mathrm{~min}$ products (Scheme 1). It is quite clear that the NMR results are consistent with the C-22 substituted oxime structures, rather than the corresponding C-22 nitroso derivative. Specifically, the C-22 chemical shifts of 152.1 and $148.5 \mathrm{ppm}$ are consistent with the fact that they stem from the quaternary carbons of the oxime structures proposed. Furthermore, the absence of ${ }^{1} \mathrm{H}$ signals on $\mathrm{C}-22$ positions of both the $22.6 \mathrm{~min}$ and 27.0 min products is also supportive toward the oxime structures. The driver for 
favoring the oximes may be attributable to the capability for the oximes to conjugate with the 3,5-dihydro-4-oxoimidazole ring.

The 2D NMR results are also consistent with the two oxime structures assigned. For example, the HMBC correlations of H-26 $\left(=\mathrm{N}-\mathrm{O}-\mathrm{H}, \delta_{\mathrm{H}} 11.6 \mathrm{ppm}, 1 \mathrm{H}, \mathrm{s}\right)$ with $\mathrm{C}-22\left(\delta_{\mathrm{C}} 148.6 \mathrm{ppm}\right)$ in the 22.6 min product and $\mathrm{H}-26\left(=\mathrm{N}-\mathrm{O}-\mathrm{H}, \delta_{\mathrm{H}} 12.1 \mathrm{ppm}, 1 \mathrm{H}, \mathrm{s}\right)$ with $\mathrm{C}-22\left(\delta_{\mathrm{C}} 152.1 \mathrm{ppm}\right)$ in the 27.0 min product (Fig. 6) indicate that both products are irbesartan oximes. In order to assign the configuration for the two isomeric irbesartan oximes, NOESY experiments were performed and a cross space correlation between $\mathrm{H}-26\left(\mathrm{~N}-\mathrm{O}-\mathrm{H}, \delta_{\mathrm{H}} 12.1 \mathrm{ppm}, 1 \mathrm{H}\right)$ and $\mathrm{H}-14\left(\delta_{\mathrm{H}} 4.98,2 \mathrm{H}, \mathrm{s}\right)$ was present only in the 27.0 min product, indicating that the 27.0 min product is the $Z$-oxime derivative of irbesartan (Fig. 7).

\subsection{Plausible fragmentation pathways of protonated irbesartan and its two oxime} derivatives

With the structures of the two oximes unequivocally determined based on the results from the above LC-PDA/UV-high resolution $\mathrm{MS}^{\mathrm{n}}$ and 1D/2D NMR experiments, plausible fragmentation pathways of the protonated irbesartan and its two oxime derivatives are proposed in Schemes 2 and 3, respectively.

\subsection{Product distributions in the reactions of irbesartan with nitrous acid under} various different conditions

In the first reaction between irbesartan and nitrous acid, no trace of the hypothetical $N$-nitrosoirbesartan could be found by the analysis of the reaction solution with the LC-PDA/UV-high resolution MS method (refer to Section 4.4) 
under the single-ion-detection mode (SIM), which had a detection limit of $60 \mathrm{ppb}$. In order to explore the possibility that $N$-nitrosoirbesartan might be formed under different reaction conditions, an additional 9 sets of reactions were carried out. In these experiments, nitrous acid was generated from in situ reaction of $\mathrm{NaNO}_{2}$ with either $\mathrm{HCl}$, acetic acid, or phosphate buffer. The reaction parameters that were systematically varied include 1) molar ratios of $\mathrm{NaNO}_{2}$ versus that of irbesartan (from 0.62 to 3.1 ), 2) $\mathrm{pH}$ of aqueous co-solvents (from $<1$ to 6.8 ), 3) reaction time (from 6 to $18 \mathrm{~h}$ ), 4) reaction temperature (from 10 to $40^{\circ} \mathrm{C}$ ), and 5) organic co-solvents (NMP or Xylene-NMP). In spite of all the efforts, no trace of the hypothetical $N$-nitrosoirbesartan could be found under all the above reaction conditions: under the SIM detection mode (LOD: $30 \mathrm{ppb)}$ of an LC-MS method (refer to Section 4.5), the only reaction products that could be observed were the two oxime derivatives of irbesartan, with the predominant formation of the $Z$-isomer (yields varying between $\sim 14 \%$ to $95 \%$ ). The theoretically possible $N$-nitrosoirbesartan would be the one where the NO group is attached to the tetrazole moiety of the biphenyl group as speculated in several websites; ${ }^{8}$ its non-existence in the reactions between irbesartan and nitrous acid is probably due to the poor nucleophilicity of the tetrazole moiety toward the electrophilic NO moiety. The details of the reactions of irbesartan with nitrous acid are summarized in Table 2.

\subsection{Analysis of irbesartan commercial batches for irbesartan oximes and the hypothetical $N$-nitrosoirbesartan}

Since the report of trace amount of NDMA in valsartan in July, 2018 and the 
subsequent events related to ranitidine, metformin and other medicines, regulatory agencies have issued a number of guidelines and guidance documents, in which current limits for $N$-nitrosoamines are established. ${ }^{5}$ For example, according to the assessment report of "Lessons learnt from presence of $N$-nitrosamine impurities in sartan medicines" issued by EMA (European Medicines Agency, Procedure number: EMA/526934/2019), $N$-nitrosoamine impurities with no PDE or AI data, or cannot be justified based on QSAR relationship, the maximum exposure of these impurities is limited to $18 \mathrm{ng} /$ day. $^{5 \mathrm{a}}$ On the other hand, FDA set the limit for these $N$-nitrosoamine impurities at $26.5 \mathrm{ng} /$ day based on the $\mathrm{TD}_{50}$ data of NDEA. ${ }^{5 \mathrm{~b}}$ As the maximum dosage of irbesartan for human is $300 \mathrm{mg} / \mathrm{day},{ }^{11}$ the presence of the hypothetical $N$-nitrosoirbesartan would only be allowed at no more than $60 \mathrm{ppb}(18 \mathrm{ng} / \mathrm{day} \div 300$ $\mathrm{mg}$ /day) in irbesartan commercial batches, if the more restrictive EMA limit of 18 ng/day is adopted. Hence, the LC-MS limit test method with SIM detection mode (refer to Section 4.5; LOD: $30 \mathrm{ppb}$, with irbesartan Z-oxime as the model reference compound) was employed to analyze a number of representative commercial batches of irbesartan. The results revealed neither presence of $N$-nitrosoirbesaratan nor irbesartan oximes, which is consistent with the risk assessment for our irbesartan chemical process.

\subsection{In silico toxicological evaluation}

Based on our study as presented above, there is a remote "theoretical" possibility that oxime might be present in irbesartan. Since the oxime moiety is not an obvious alerting structure, ${ }^{12}$ in normal situation it may be controlled as a regular impurity. 
Nevertheless, due to the ramification from the NDMA and subsequent events, we performed in silico toxicological evaluation of the irbesartan oximes identified in this study with the toxicological assessment software CASE Ultra (version: vl.8.0.2). The QSAR module calculated the probability for the oxime impurities being Ames positive was $15.2 \%$ (negative) using the model GT1_BMUT. Moreover, the impurities were predicted to be $36.4 \%$ (negative) in the reference database of the expert rule system GT_EXPERT. According to the algorithm of CASE Ultra, the calculated probability is lower than the model's classification threshold and not within the gray zone. Furthermore, the Konsolidator module of CASE Ultra suggested that the outcome was negative for the query chemicals. Based on the overall evaluation by CASE Ultra, irbesartan oximes can be justified as Class 5 substances, i.e., they may be controlled as regular impurities.

\section{CONCLUSIONS}

Through the systematic study of the reactions between irbesartan and nitrous acid, the reaction products formed are found to be the $E$-oxime and $Z$-oxime derivatives of irbesartan, with the $Z$-isomer as the predominant product. No trace of the hypothetical $N$-nitrosoirbesartan can be detected in the reaction solutions of irbesartan with nitrous acid or in commercial batches of irbesartan. Despite the fact that in silico evaluation suggests that the two irbesartan oximes may be controlled as regular impurities, analysis of representative irbesartan commercial batches by a sensitive and accurate LC-MS method indicates that the oximes are not detected. 


\section{EXPERIMENTAL SECTION}

4.1. General. Unless otherwise noted, all solvents and reagents for reactions were used without further purification. All solvents and reagents utilized in HPLC analyses were HPLC grade. All solvents and reagents employed in LC-MS analyses were of mass purity grade. ${ }^{1} \mathrm{H}$ and ${ }^{13} \mathrm{C}$ NMR and $2 \mathrm{D}$ NMR spectra of the compounds were acquired on an Agilent $400 \mathrm{MHz}$ spectrometer at $25^{\circ} \mathrm{C} .{ }^{1} \mathrm{H}$ and ${ }^{13} \mathrm{C}$ resonances were assigned and confirmed by results from the following 2D NMR experiments: gCOSY, gHSQC, gHMBC and NOESY. Chemical shifts are reported in ppm ( $\delta$ units) relative to the internal standard of tetramethylsilane $\left[\left(\mathrm{CH}_{3}\right)_{4} \mathrm{Si}, \mathrm{TMS}\right]$ or residual signal of DMSO- $d_{5}$; coupling constants are reported in hertz $(\mathrm{Hz})$. Multiplicities are as follows: $\mathrm{s}=$ singlet, $\mathrm{d}=$ doublet, $\mathrm{t}=$ triplet, $\mathrm{q}=$ quartet, $\mathrm{dd}=$ doublet of doublets, $\mathrm{m}=$ multiplet. Irbesartan (CAS\# 138402-11-6) is a product of Huahai Pharmaceutical. Sodium nitrite (CAS\# 7632-00-0), concentrated hydrochloric acid (37\%, CAS\# 7647-01-0), $N$-methyl pyrrolidone (NMP, CAS\# 872-50-4), disodium hydrogen phosphate $\left(\mathrm{Na}_{2} \mathrm{HPO}_{4}, \mathrm{CAS} \#\right.$ 7558-79-4), sodium dihydrogen phosphate $\left(\mathrm{NaH}_{2} \mathrm{PO}_{4}, \mathrm{CAS} \#\right.$ 7558-80-7), and xylene were sourced from commercial vendors.

\subsection{Reactions of irbesartan with nitrous acid under various different conditions.}

In a $20 \mathrm{~mL}$ of round bottom flask, $3.00 \mathrm{~g}$ of irbesartan $(7.00 \mathrm{mmol})$ and $1.50 \mathrm{~g}$ sodium nitrite $(21.7 \mathrm{mmol})$ were added into $10 \mathrm{~mL}$ solvent, followed by the addition of $3 \mathrm{~mL}$ of concentrated hydrochloric acid $(36.0 \mathrm{mmol})$ or phosphate buffer $(\mathrm{pH}=4.0$ or 6.8$)$. The resulting solution was allowed to stir at $40 \pm 2^{\circ} \mathrm{C}$ or $10 \pm 2^{\circ} \mathrm{C}$ for $6 \mathrm{~h}$ or $18 \mathrm{~h}$. 
After the end of the reaction, the reaction solution was either cooled or warmed to reach room temperature, followed by analysis with either the HPLC method (Section 4.3) or LC-PDA/UV-high resolution-MS ${ }^{\mathrm{n}}$ method (Section 4.4).

\subsection{HPLC analysis for reaction solutions of irbesartan with nitrous acid. A} Thermo Scientific Dionex Ultimate 3000 HPLC system was used, which was equipped with a PDA/UV detector and an Agilent Zorbax SB-C18 column $(250 \times 4.6$ $\mathrm{mm}, 5 \mu \mathrm{m})$. The mobile phase system consisted of A (15 mM ammonium formate aqueous solution, adjusted to $\mathrm{pH} 3.0$ with formic acid) and $\mathrm{B}$ (acetonitrile), with the gradient varied according to the following program: $0 \min (25 \% \mathrm{~B}), 7 \mathrm{~min}(25 \% \mathrm{~B})$, $28 \min (60 \% \mathrm{~B}), 35 \min (60 \% \mathrm{~B}), 37 \mathrm{~min}(25 \% \mathrm{~B})$ and $45 \min (25 \% \mathrm{~B})$. The analyses were performed at a flow rate of $1.0 \mathrm{~mL} / \mathrm{min}$ for $45 \mathrm{~min}$ and a column temperature of $30^{\circ} \mathrm{C}$, with an injection volume of $10 \mu \mathrm{L}$. The wavelength was set at $220 \mathrm{~nm}$ and UV spectra were collected by the PDA/UV detector with a wavelength range of 200-400 nm.

4.4. LC-PDA/UV-QTOF-MS ${ }^{\mathrm{n}}(\mathbf{n}=\mathbf{1}, \mathbf{2})$ analyses. An Agilent HPLC instrument (1260 series, Agilent Technologies, USA) interfaced to a quadrupole time-of-flight (Q-TOF) mass spectrometer (6545 series, Agilent Technologies, USA) was used for the LC-PDA/UV-MS ${ }^{\mathrm{n}}(\mathrm{n}=1,2)$ analysis of samples. The chromatographic conditions were the same as those of the HPLC method described in Section 4.3. The Q-TOF mass spectrometer was operated under positive ESI mode with the following source parameters: drying gas flow $10 \mathrm{~L} / \mathrm{min}$, drying gas temperature $320^{\circ} \mathrm{C}$, nebulizer pressure $60 \mathrm{psi}$, source temperature $325^{\circ} \mathrm{C}$, sheath gas temperature $350^{\circ} \mathrm{C}$, sheath gas 
flow $12 \mathrm{~L} / \mathrm{min}$, nozzle voltage $600 \mathrm{~V}$, fragmentor $60 \mathrm{~V}$, skimmer $65 \mathrm{~V}$ and capillary voltage $4.0 \mathrm{kV}$. The acquisition range of $m / z$ value was $50-1,000$ and for the $\mathrm{MS}^{2}$ analyses, the collision energy was set to $30 \mathrm{eV}$.

4.5. LC-MS limit test method. An Agilent HPLC instrument (1260 series, Agilent Technologies, USA) interfaced to a single quadrupole mass spectrometer (6120 series, Agilent Technologies, USA) was used for the limit test of irbesartan oximes in irbesartan samples. A Thermo Accucore ${ }^{\mathrm{TM}}$ Phenyl-Hexyl column $(150 \times 4.6 \mathrm{~mm}, 2.6$ $\mu \mathrm{m})$ was used. The mobile phase system consisted of A ( $0.1 \%$ formic acid in water) and B (acetonitrile), with the gradient varied according to the following program: 0 $\min (50 \% \mathrm{~B}), 7 \min (50 \% \mathrm{~B}), 7.01 \min (100 \% \mathrm{~B}), 15 \min (100 \% \mathrm{~B}), 15.01 \min (50 \%$ B) and $20 \mathrm{~min}(50 \% \mathrm{~B})$. The analyses were performed at a flow rate of $0.8 \mathrm{~mL} / \mathrm{min}$ for $20 \mathrm{~min}$ and a column temperature of $25^{\circ} \mathrm{C}$, with an injection column of $5 \mu \mathrm{L}$. The LC-MS mass spectrometer was operated under positive ESI mode with the following parameters: scan mode SIM, SIM ion $(\mathrm{m} / \mathrm{z} 458)$, drying gas flow $10 \mathrm{~L} / \mathrm{min}$, drying gas temperature $350^{\circ} \mathrm{C}$, fragmentor $130 \mathrm{~V}$, nebulizer pressure $60 \mathrm{psi}$, peak width $0.1 \mathrm{~min}$, gain factor 1.0 , and capillary voltage $3.0 \mathrm{kV}$. The acquisition range of $\mathrm{m} / \mathrm{z}$ value was 50-1,000 and the mass acquisition time was $4.8 \sim 6.5 \mathrm{~min}$.

The irbesartan $Z$-oxime was used as the reference sample. The signal of $\mathrm{m} / \mathrm{z} 458$, resulting from the protonated irbesartan oximes under ESI positive SIM mode, is employed as the semi-quantitation ion in the study. The concentration of the irbesartan sample solution was $10 \mathrm{mg} / \mathrm{mL}$, while the concentration of irbesartan $Z$-oxime in the LOD solution was $0.3 \mathrm{ng} / \mathrm{mL}$, which was $30 \mathrm{ppb}$ relative to the sample concentration. 
Injection of the LOD solution yielded the peak of irbesartan $Z$-oxime at $5.292 \mathrm{~min}$ with $\mathrm{S} / \mathrm{N}$ of 11 . The concentration of irbesartan $Z$-oxime in the "system suitability solution" was $0.6 \mathrm{ng} / \mathrm{mL}$, which was $60 \mathrm{ppb}$ relative to the sample concentration. The RSD of the six replicate injections of the "system suitability solution" was $8.2 \%$ (Table S1) and the average recovery of three spiked solutions at 60 ppb was $108.1 \%$. These results indicated that the LC-MS limit test method is sensitive with adequate precision and accuracy.

4.6 Isolation of the $22.6 \mathrm{~min}$ and $27.0 \mathrm{~min}$ products. A Shimadzu preparative high performance liquid chromatography with a UV detector was used for isolation of the $22.6 \mathrm{~min}$ and $27.0 \mathrm{~min}$ products. A YMC-Pack ODS-AQ column $(250 \times 20 \mathrm{~mm}, 5 \mu \mathrm{m})$ was used. The mobile phase system consisted of A (15 mM ammonium formate aqueous solution, adjusted to $\mathrm{pH} 3.0$ with formic acid) and $\mathrm{B}$ (acetonitrile), with the gradient varied according to the following program: $0 \min (25 \% \mathrm{~B}), 7 \mathrm{~min}(25 \% \mathrm{~B})$, $28 \min (60 \% \mathrm{~B}), 35 \min (60 \% \mathrm{~B}), 37 \mathrm{~min}(25 \% \mathrm{~B})$ and $45 \min (25 \% \mathrm{~B})$. The analyses were performed at a flow rate of $19.0 \mathrm{~mL} / \mathrm{min}$ for $45 \mathrm{~min}$ and the column temperature was ambient. The injection volume for the 22.6 min product was $2 \mathrm{~mL}$, while the injection volume for the 27.0 min product was $3 \mathrm{~mL}$. The wavelength was set at 220 $\mathrm{nm}$. The fractions at $22.1 \sim 22.6 \mathrm{~min}$ for the $22.6 \mathrm{~min}$ product and $26.1 \sim 27.1 \mathrm{~min}$ for the 27.0 min product were collected. The fractions collected were pooled and then concentrated by lyophilization; approximately $20 \mathrm{mg}$ of the $22.6 \mathrm{~min}$ product and 190 mg of the 27.0 min product were obtained with $85 \%$ and $97 \%$ HPLC purity, respectively, for NMR structural determination. 


\section{AUTHOR INFORMATION}

\section{Corresponding Author}

Min Li-Center of Excellence for Modern Analytical Technologies (CEMAT), Zhejiang Huahai Pharmaceutical Co. Ltd., Xunqiao, Linhai, Zhejiang, 317204, PR China; Huahai US, Inc., 700 Atrium Drive, Somerset, NJ 08873, USA; email: minli88@yahoo.com.

\section{Authors}

Jinsheng Lin-Center of Excellence for Modern Analytical Technologies (CEMAT), Zhejiang Huahai Pharmaceutical Co. Ltd., Xunqiao, Linhai, Zhejiang, 317204, PR China

Qiang Zhou- Center of Excellence for Modern Analytical Technologies (CEMAT), Zhejiang Huahai Pharmaceutical Co. Ltd., Xunqiao, Linhai, Zhejiang, 317204, PR China

Ru Jia-Center of Excellence for Modern Analytical Technologies (CEMAT), Zhejiang Huahai Pharmaceutical Co. Ltd., Xunqiao, Linhai, Zhejiang, 317204, PR China

Wentao Liu-Center of Excellence for Modern Analytical Technologies (CEMAT), Zhejiang Huahai Pharmaceutical Co. Ltd., Xunqiao, Linhai, Zhejiang, 317204, PR China

Huacui Hou-Center of Excellence for Modern Analytical Technologies (CEMAT), Zhejiang Huahai Pharmaceutical Co. Ltd., Xunqiao, Linhai, Zhejiang, 317204, PR China 
Jian Ma-Center of Excellence for Modern Analytical Technologies (CEMAT), Zhejiang Huahai Pharmaceutical Co. Ltd., Xunqiao, Linhai, Zhejiang, 317204, PR China

Dan Li-Center of Excellence for Modern Analytical Technologies (CEMAT), Zhejiang Huahai Pharmaceutical Co. Ltd., Xunqiao, Linhai, Zhejiang, 317204, PR China

Nuo Chen-Center of Excellence for Modern Analytical Technologies (CEMAT), Zhejiang Huahai Pharmaceutical Co. Ltd., Xunqiao, Linhai, Zhejiang, 317204, PR China

Wenbin Chen-Center of Excellence for Modern Analytical Technologies (CEMAT), Zhejiang Huahai Pharmaceutical Co. Ltd., Xunqiao, Linhai, Zhejiang, 317204, PR China

Jian Ye-Center of Excellence for Modern Analytical Technologies (CEMAT), Zhejiang Huahai Pharmaceutical Co. Ltd., Xunqiao, Linhai, Zhejiang, 317204, PR China

Wenping Hu-Center of Excellence for Modern Analytical Technologies (CEMAT), Zhejiang Huahai Pharmaceutical Co. Ltd., Xunqiao, Linhai, Zhejiang, 317204, PR China

Wenquan Zhu-Center of Excellence for Modern Analytical Technologies (CEMAT), Zhejiang Huahai Pharmaceutical Co. Ltd., Xunqiao, Linhai, Zhejiang, 317204, PR China 


\section{Notes}

The authors declare no conflict financial interest.

\section{ACKNOWLEDGMENTS}

We gratefully acknowledge Dr. Zunjun Liang of Technology Research Center,

Chuannan Plant of Huahai Pharmaceutical, for providing irbesartan samples. 


\section{REFERENCES}

(1) (a) Bozal, B.; Doğan-Topal, B.; Uslu, B.; Özkan, A.; Aboul-Enein, H. Quantitative analysis of irbesartan in pharmaceuticals and human biological fluids by voltammetry. Anal. Lett. 2009, 42, 2322-2338. (b) Ganapuram, B.; Alle, M.; Dadigala, R.; Kotu, G.;

Gutten V. Development, evaluation and characterization of surface solid dispersion for solubility and dispersion enhancement of irbesartan. J. Pharm. Res. 2013, 7, $472-477$.

(2) Lijinsky, W.; Reuber, M. Carcinogenesis in rats by nitrosodimethylamine and other nitrosomethylalkylamines at low dose. Cancer. Lett. 1984, 22, 83-88.

(3) FDA announces voluntary recall of several medicines containing valsartan following detection of an impurity. Published on July 13, 2018.

https://www.fda.gov/news-events/press-announcements/fda-announces-voluntary-reca 11-several-medicines-containing-valsartan-following-detection-impurity (Accessed on December 07, 2021).

(4) (a) Statement alerting patients and health care professionals of NDMA found in samples of ranitidine. Released on September 13, 2019.

https://www.fda.gov/news-events/press-announcements/statement-alerting-patients-an d-health-care-professionals-ndma-found-samples-ranitidine. (b) Statement from Janet Woodcock, M.D., Director of FDA's Center for Drug Evaluation and Research, on impurities found in diabetes drugs outside the U.S. Released on December 05, 2019. https://www.fda.gov/news-events/press-announcements/statement-janet-woodcock-m d-director-fdas-center-drug-evaluation-and-research-impurities-found. 
(5) (a) Lessons learnt from presence of N-nitrosamine impurities in sartan medicines, an assessment report issued by European Medicines Agency (EMA), EMA/526934/2019. Available from:

https://www.ema.europa.eu/en/documents/report/lessons-learnt-presence-n-nitrosamin e-impurities-sartan-medicines en.pdf. (b) Control of nitrosamine impurities in human drugs, guidance for industry, docket number: FDA-2020-D-1530. Published in September 2020 and content current as of 02/24/2021.

https://www.fda.gov/regulatory-information/search-fda-guidance-documents/control-n itrosamine-impurities-human-drugs.

(6) ICH guidelines, M7 (R1): Assessment and control of DNA reactive (mutagenic) impurities in pharmaceuticals to limit potential carcinogenic (revision 1), International Conference on Harmonization. Available from:

https://database.ich.org/sites/default/files/M7_R1_Guideline.pdf.

(7) Lupin Pharmaceuticals, Inc. issues voluntarily nationwide recall of all irbesartan tablets and irbesartan and hydrochlorothiazide tablets due to potential presence of N-nitrosoirbesartan impurity. Issued on July 13, 2018.

https://www.fda.gov/safety/recalls-market-withdrawals-safety-alerts/lupin-pharmaceut $\underline{\text { icals-inc-issues-voluntarily-nationwide-recall-all-irbesartan-tablets-and-irbesartan }}$ (Accessed on December 07, 2021).

(8) (a) Nitroso Irbesartan. https://www.simsonpharma.com/product/nitroso-irbesartan (Accessed on December 07, 2021). (b) Nitroso Irbesartan. https://www.synzeal.com/en/nitroso-irbesartan (Accessed on December 07, 2021). (c) 
N-Nitroso Irbesartan. https://www.agnitio.co.in/product/n-nitroso-irbesartan/ (Accessed on December 07, 2021). (d) Nitroso Irbesartan. https://www.pharmaffiliates.com/en/nitroso-irbesartan-pa090141000.html (Accessed on December 07, 2021).

(9) (a) Bernhart, C.; Perreaut, P.; Ferrari, B.; Muneaux, Y.; Assens, J.; Clement, J.; Haudricourt, F.; Muneaux, C.; Taillades, J.; Vignal, M.; Gougat, J.; Guiraudou, P.; Lacour, C.; Roccon, A.; Cazaubon, C.; Brelihre, J.; Fur, G.; Nisato, D. A new series of imidazolones: Highly specific and potent nonpeptide $\mathrm{AT}_{1}$ angiotensin II receptor antagonists. J. Med. Chem. 1993, 36, 3371-3380. (b) Ye, P.; Sargent, K.; Stewart, E.; Liu, J.; Yohannes, D.; Yu, L. Novel and expeditious microwave-assisted three-component reactions for the synthesis of spiroimidazolin-4-ones. J. Org. Chem. 2006, 71, 3137-3140.

(10) (a) Wang, G.; Fiske, J.; Jennings, S.; Tomasella, F.; Palaniswamy, V. Identification and control of a degradation product in Avapro ${ }^{\mathrm{TM}}$ film-coated tablet: low dose formulation. Pharm. Dev. Technol. 2008, 13, 393-399. (b) Li, M. Chapter 5, Drug-excipient interactions and adduct formation, Organic Chemistry of Drug Degradation, 2012, RSC publishing, Cambridge, UK, page 159.

(11) Sartan medicines: companies to review manufacturing processes to avoid presence of nitrosamine impurities, an assessment report issued by European Medicines Agency (EMA), EMA/44960/2019. Available from: https://www.ema.europa.eu/en/documents/press-release/sartan-medicines-companies-r eview-manufacturing-processes-avoid-presence-nitrosamine-impurities_pr.pdf 
(12) (a) Müller, L., Mauthe, R., Riley, C., Andino, M., Antonis, D., Beels, C., Joseph DeGeorge, J., De Knaep, A., Dean Ellison, D., Fagerland, J., Frank, R., Fritschel, B., Galloway, S., Harpur, E., Humfrey, C., Jacks, A., Jagota, N., John Mackinnon, J., Mohan, G., Ness, D., O’Donovan, M., Smith, M., Vudathala, G., Yotti, L. A rationale for determining, testing, and controlling specific impurities in pharmaceuticals that possess potential for genotoxicity. Regul. Toxicol. Pharm. 2006, 44, 198-211. (b) Benigni, R.; Bossa, C. Mechanisms of chemical carcinogenicity and mutagenicity: a review with implications for predictive toxicology. Chem. Rev. 2011, 111, 2507-2536. 


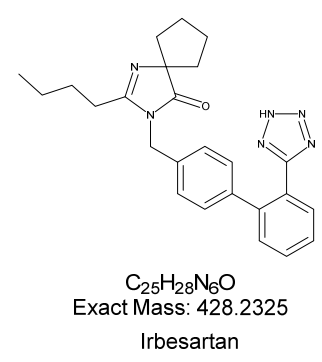

A

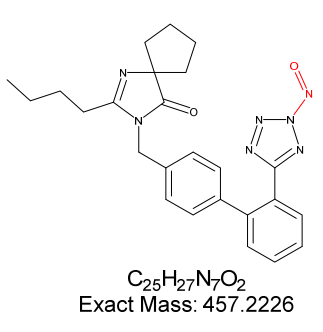

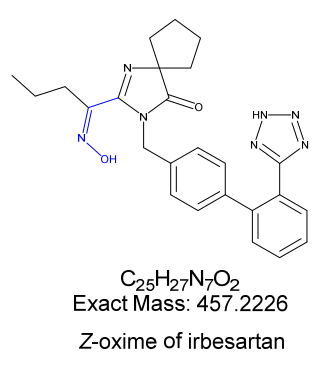

C

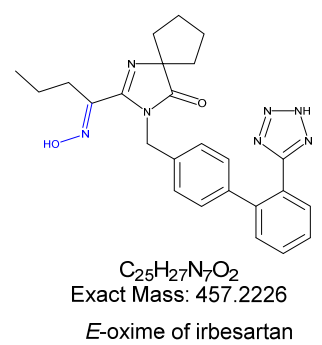

D

Fig. 1. Structures of irbesartan (A), the hypothetical $N$-nitrosoirbesartan (B), and the two oxime derivatives of irbesartan $(\mathrm{C}$ and $\mathrm{D})$.

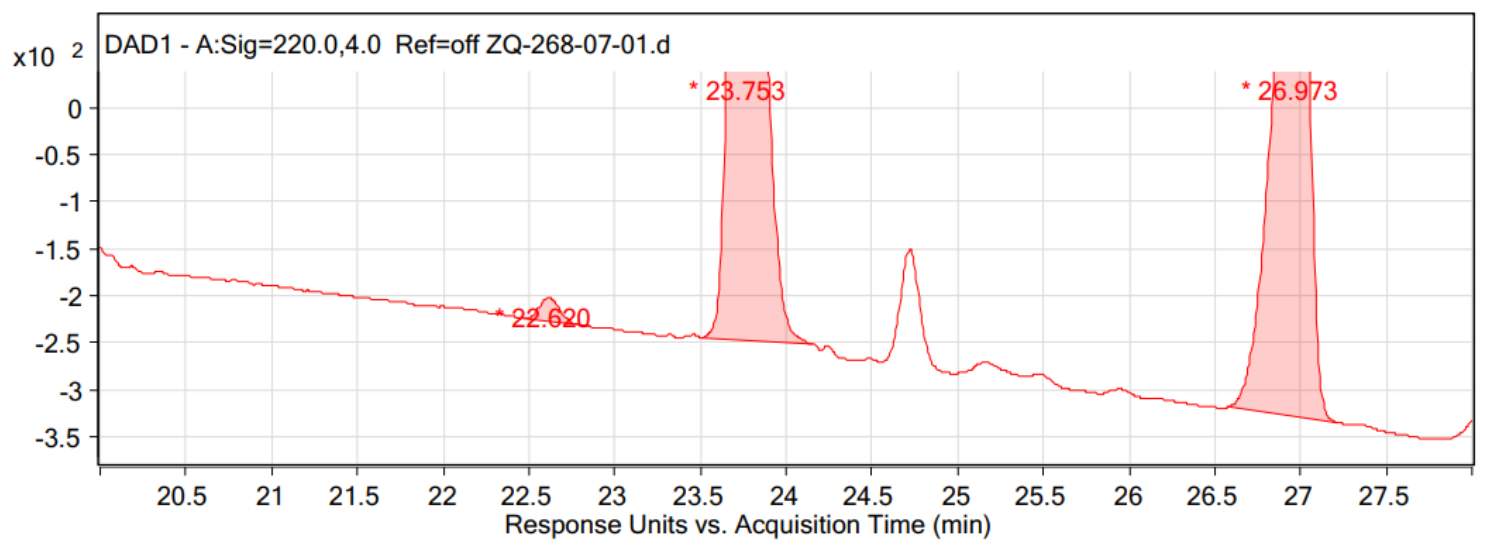

Fig. 2. HPLC chromatogram at $220 \mathrm{~nm}$ of the reaction solution of irebesartan and sodium nitrite in acidic condition. The two reaction products of irbesartan were observed at $22.620 \mathrm{~min}$ and $26.973 \mathrm{~min}$. 

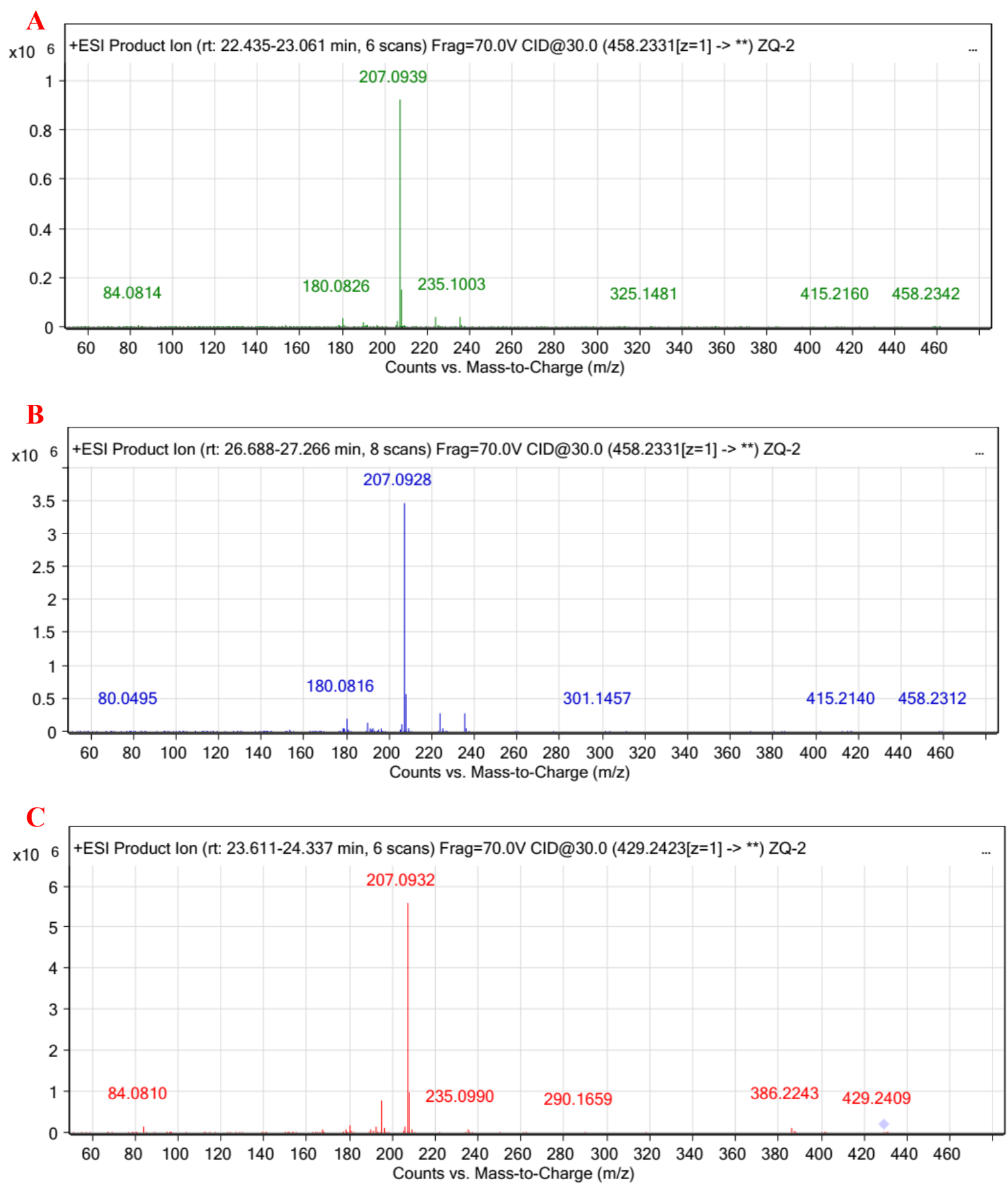

Fig. 3. LC-ESI-MS/MS spectra of the protonated ions of $22.6 \mathrm{~min}$ and $27.0 \mathrm{~min}$ products (both of the precursor ions shown at $m / z 458$, A \& B) and protonated irbesartan $(\mathrm{m} / \mathrm{z} 429, \mathrm{C})$ under the collision energy of $30 \mathrm{eV}$. 


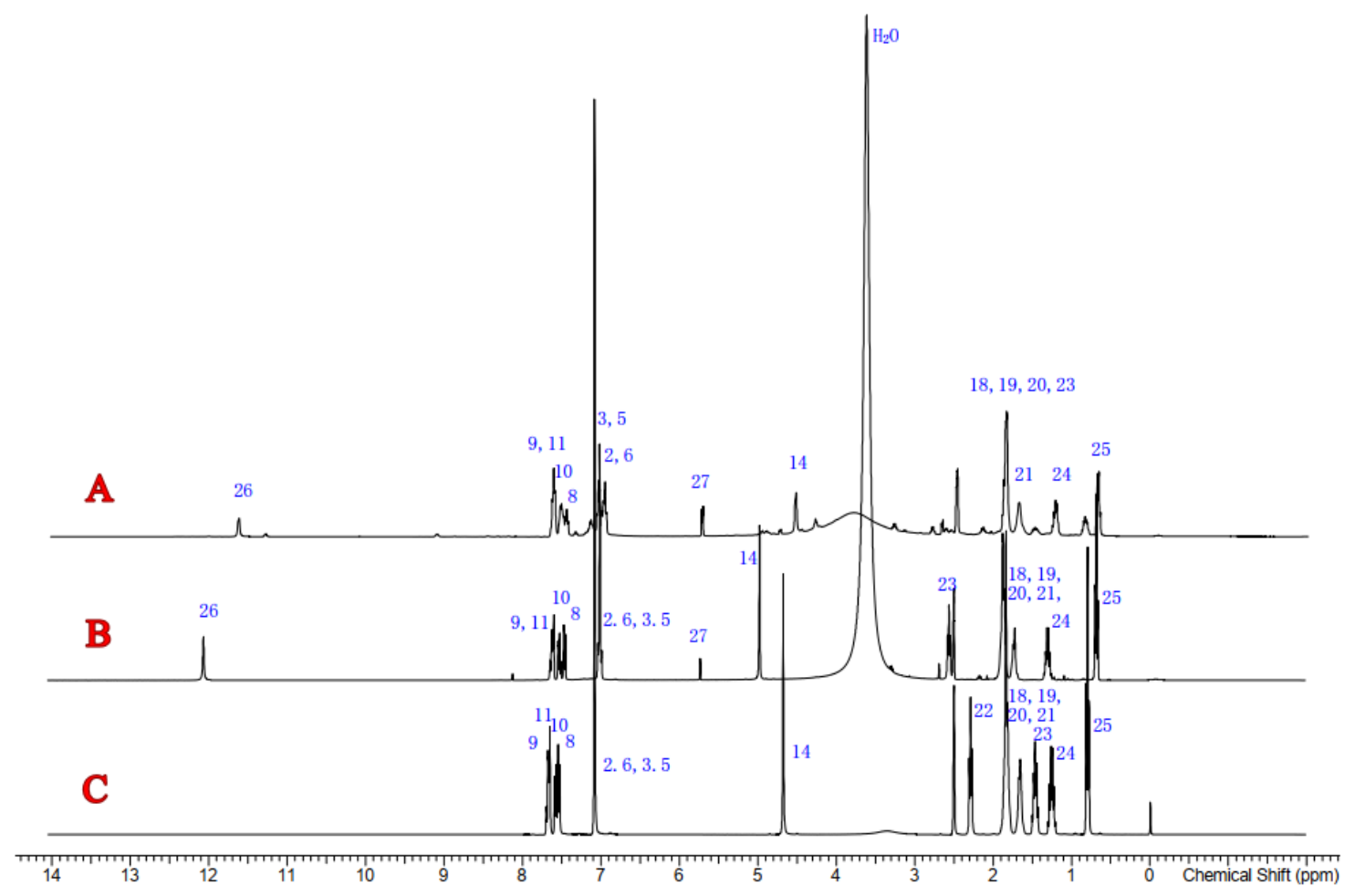

Fig. 4. Overlaid ${ }^{1} \mathrm{H}-\mathrm{NMR}$ spectra of the 22.6 min product (A), 27.0 min product (B) and irbesartan (C).

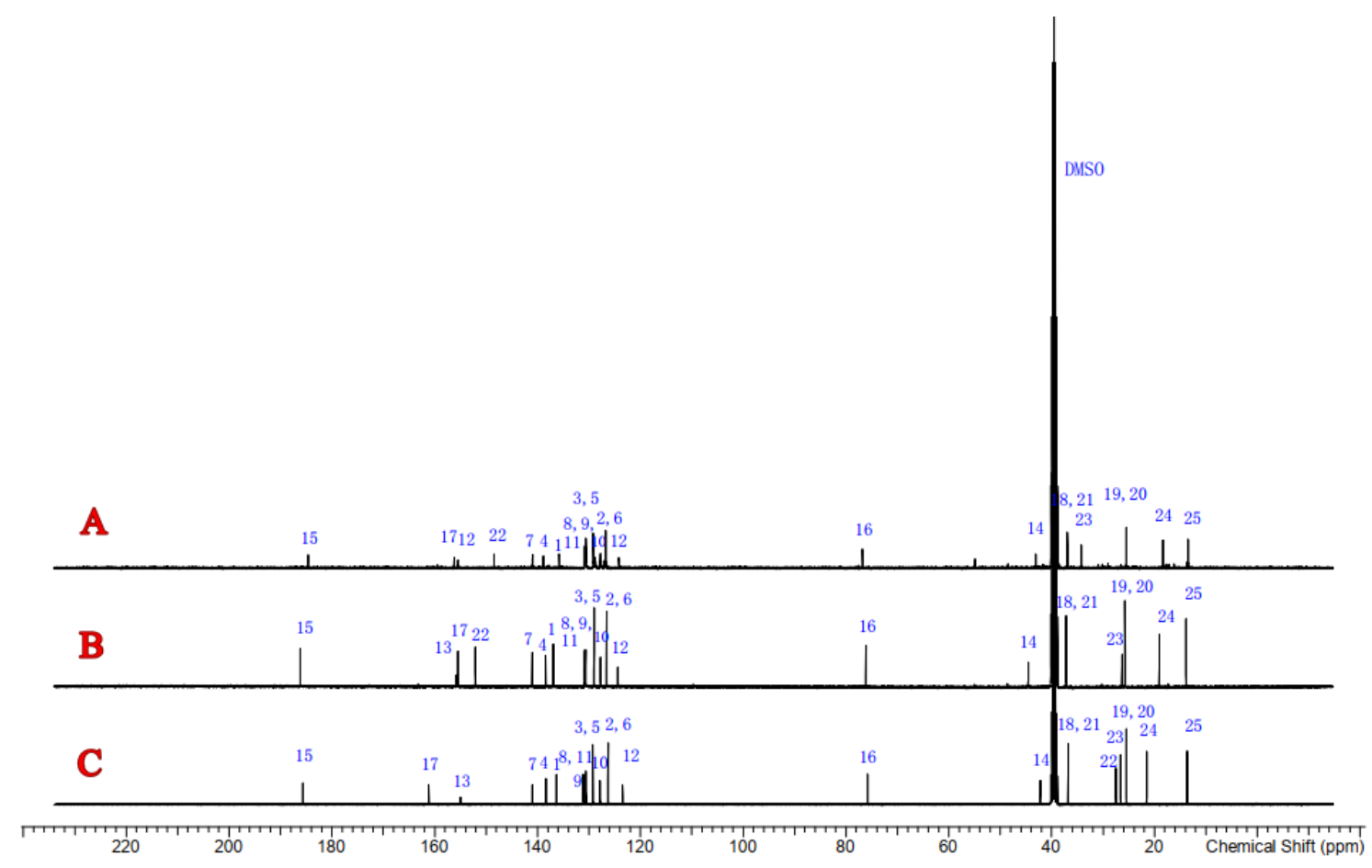

Fig. 5. Overlaid ${ }^{13} \mathrm{C}-\mathrm{NMR}$ spectra of irbesartan E-oxime (22.6 min product, A), irbesartan Z-oxime (27.0 min product, B) and irbesartan (C). 
A

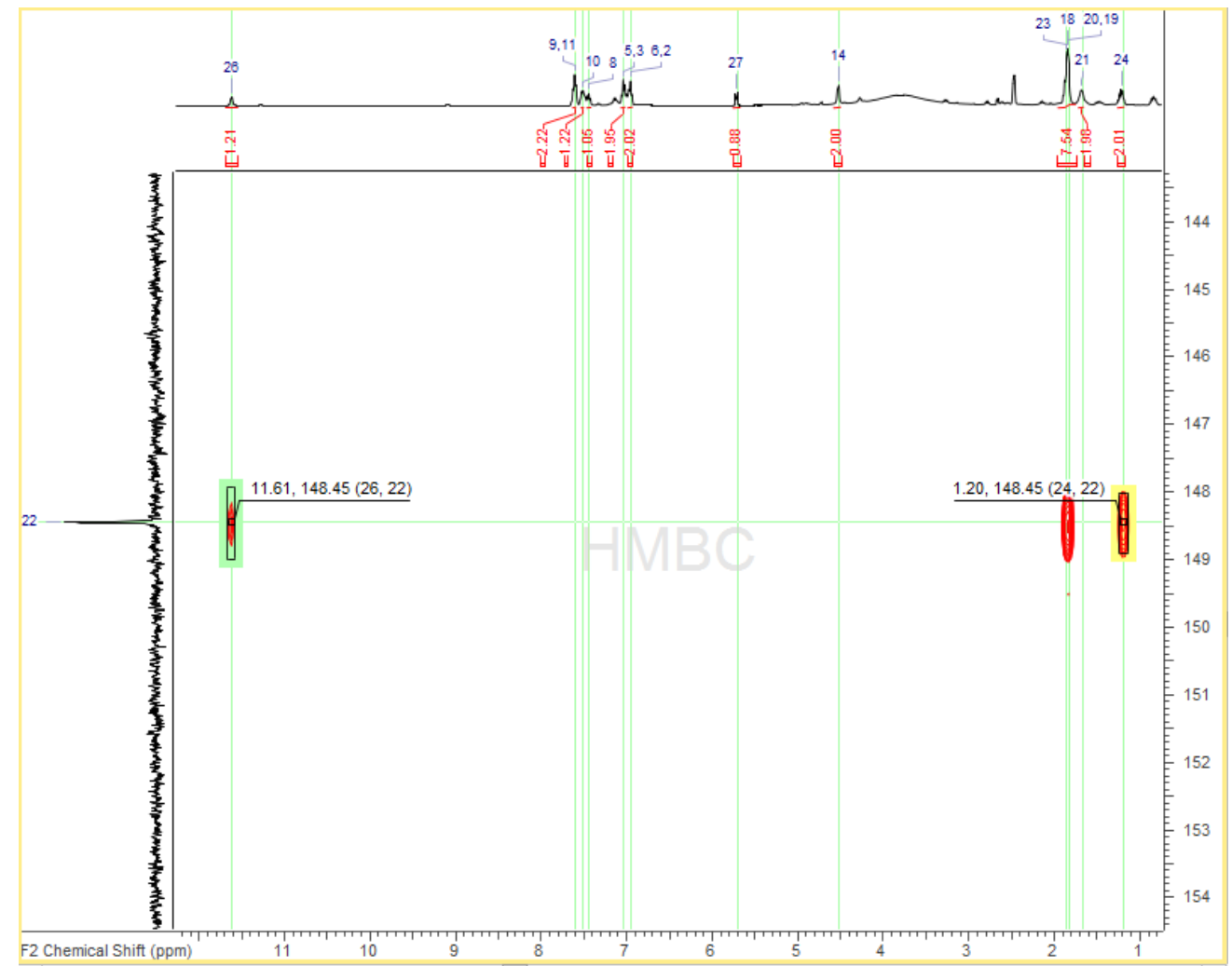

B

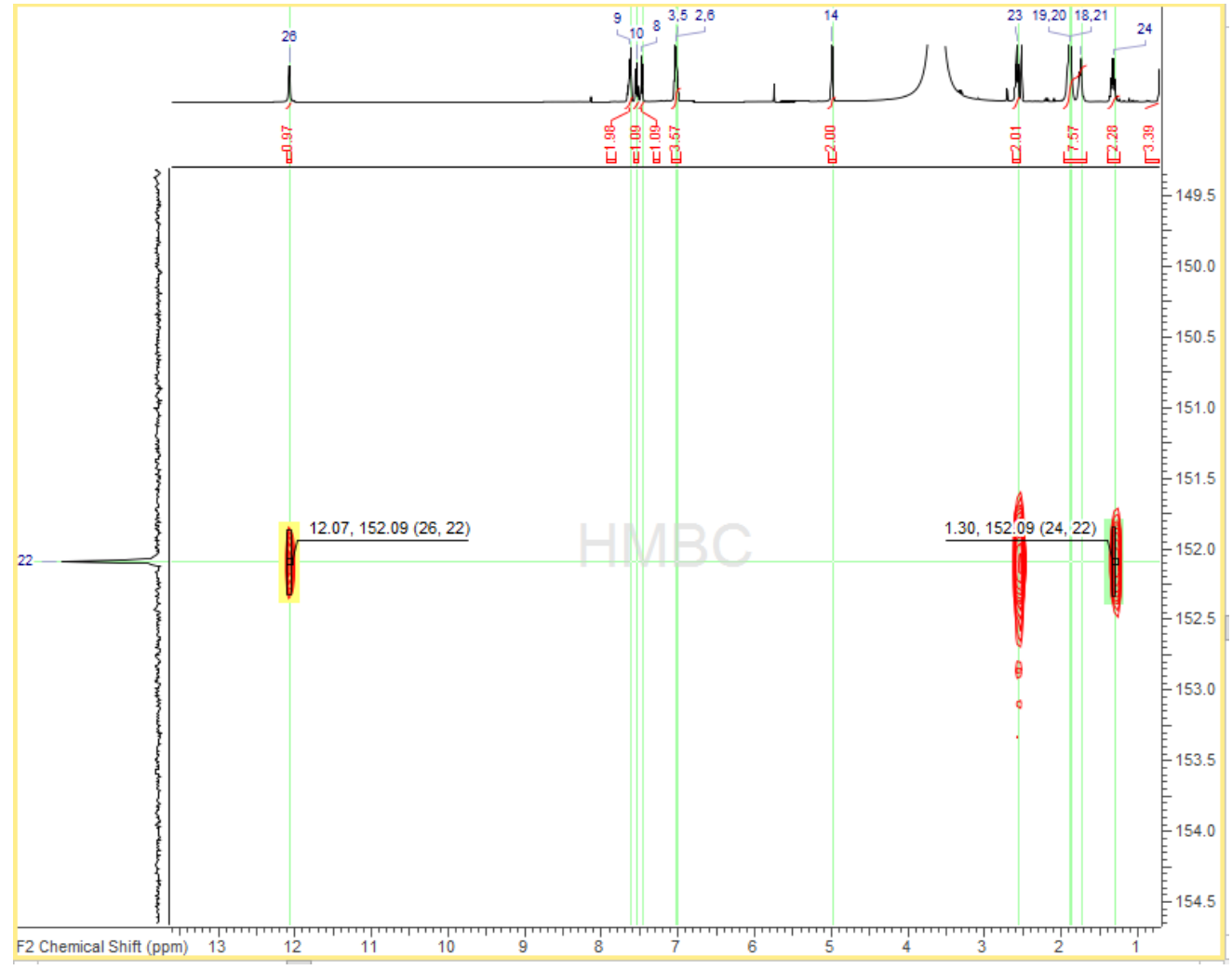

Fig. 6. A) Key HMBC correlations of irbesartan $E$-oxime (22.6 min product) and B) irbesartan $Z$-oxime (27.0 min product). 


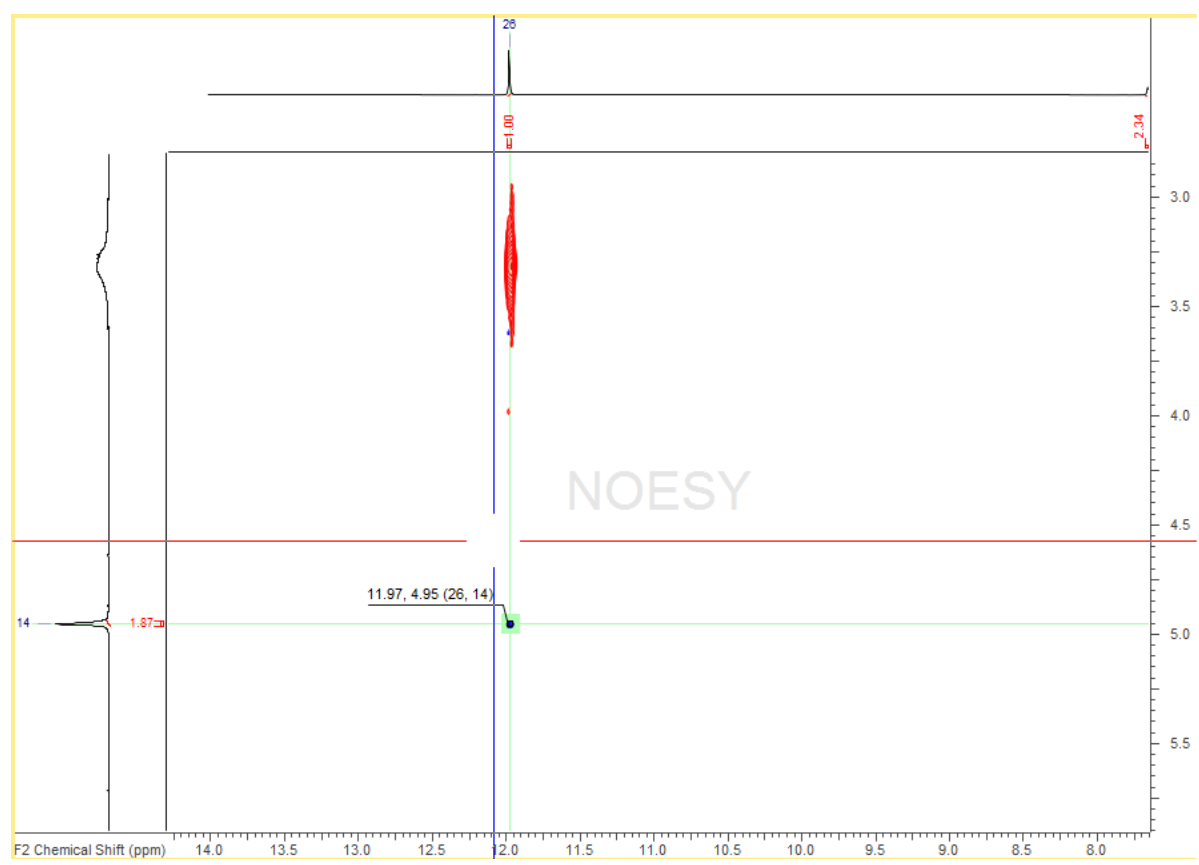

Fig. 7. Key NOESY correlation of irbesartan Z-oxime (27.0 min product).

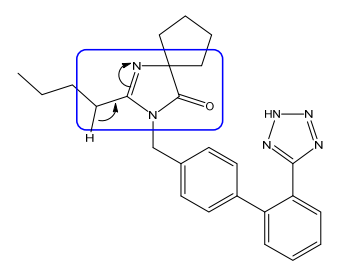

Irbesartan

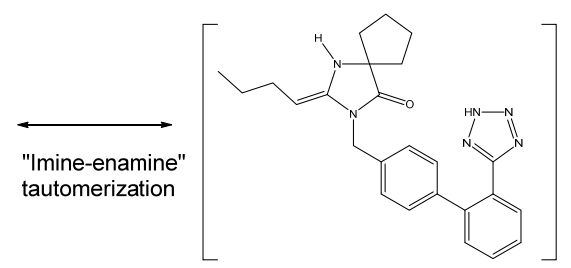

Irbesartan enamine

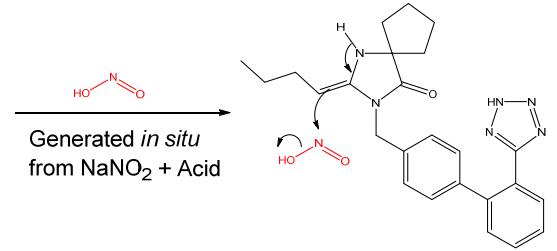

Nucleophilic attack to nitrous acid

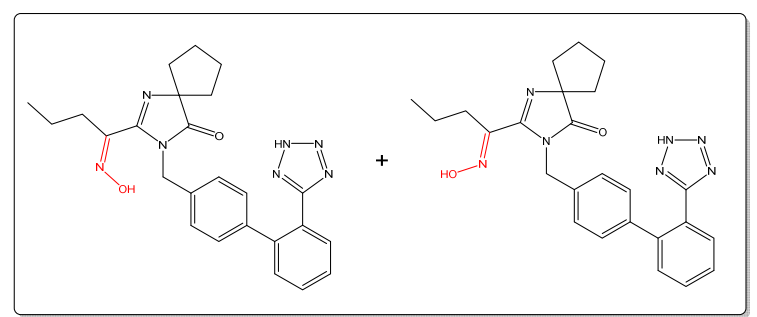

Irbesartan Z-oxime Predominant

Irbesartan E-oxime

Minor

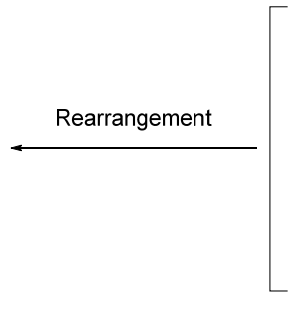
irbesartan intermediate

Scheme 1. Proposed formation mechanism of the $E$ - and $Z$-oximes of irbesartan in the reaction of irbesartan with nitrous acid. 


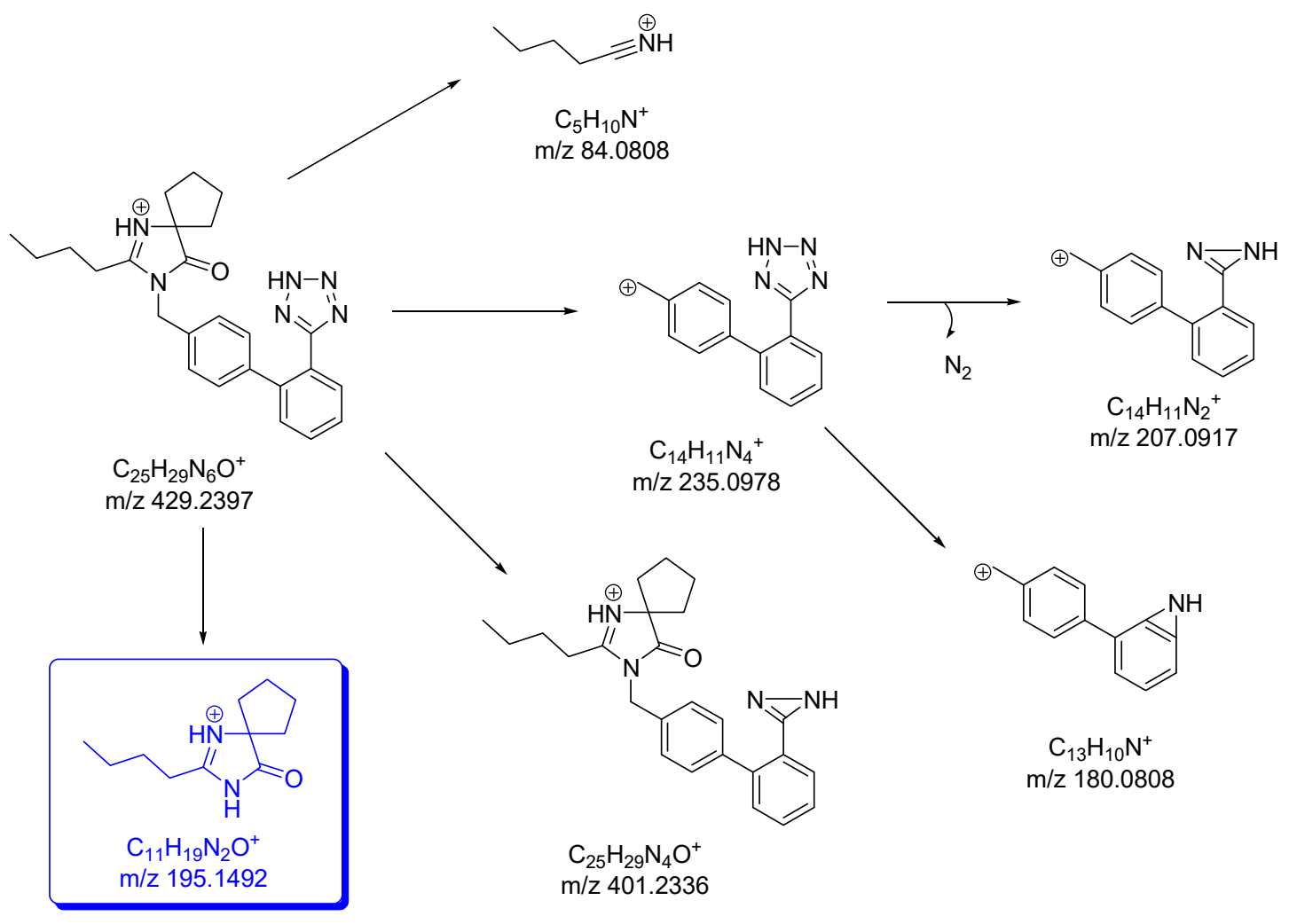

Scheme 2. Proposed LC-MS/MS fragmentation pathway of protonated irbesartan.

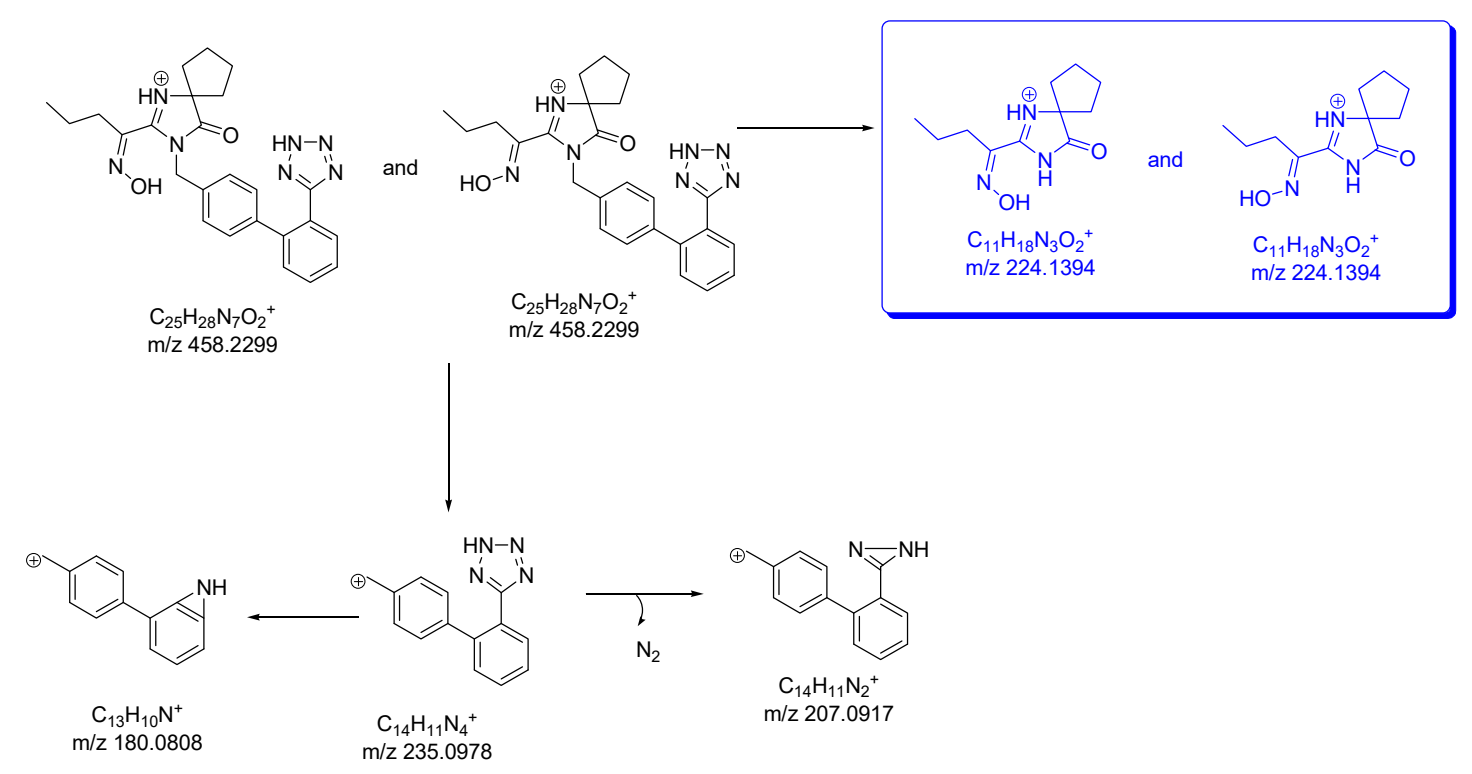

Scheme 3. Proposed LC-MS/MS fragmentation pathway of protonated irbesartan oximes. 
Table 1. ${ }^{1} \mathrm{H}$ and ${ }^{13} \mathrm{C}$ NMR spectroscopic data of irbesartan (DMSO- $d_{6}$ ), irbesartan $E$-oxime and irbesartan $Z$-oxime (DMSO- $d_{6}, \delta$ in ppm)

\begin{tabular}{|c|c|c|c|c|c|c|}
\hline \multirow{2}{*}{ Position } & \multirow{2}{*}{\multicolumn{2}{|c|}{$\frac{\text { Irbesartan }}{{ }^{1} \mathrm{H} \text { shifts }{ }^{13} \mathrm{C} \text { shifts }}$}} & \multicolumn{2}{|c|}{ Irbesartan $E$-oxime } & \multicolumn{2}{|c|}{ Irbesartan Z-oxime } \\
\hline & & & ${ }^{1} \mathrm{H}$ shifts & ${ }^{13} \mathrm{C}$ shifts & ${ }^{1} \mathrm{H}$ shifts & ${ }^{13} \mathrm{C}$ shifts \\
\hline 1 & - & 136.3 & - & 135.8 & - & 136.9 \\
\hline 2,6 & 7.08 & 126.3 & $6.95(2 \mathrm{H}, \mathrm{m})$ & 126.7 & $7.01(2 \mathrm{H}, \mathrm{m})$ & 126.6 \\
\hline 3,5 & 7.08 & 129.3 & $7.03(2 \mathrm{H}, \mathrm{m})$ & 129.2 & $7.02(2 \mathrm{H}, \mathrm{s})$ & 129.0 \\
\hline 4 & - & 138.3 & - & 138.9 & - & 138.4 \\
\hline 7 & - & 141.0 & - & 141.0 & - & 141.1 \\
\hline 8 & 7.54 & 130.6 & $7.44(1 \mathrm{H}, \mathrm{m})$ & 130.5 & $7.46(1 \mathrm{H}, \mathrm{m})$ & 130.7 \\
\hline 9 & 7.68 & 131.1 & $7.60(1 \mathrm{H}, \mathrm{m})$ & 130.6 & $7.62(1 \mathrm{H}, \mathrm{m})$ & 130.8 \\
\hline 10 & 7.57 & 127.9 & $7.51(1 \mathrm{H}, \mathrm{m})$ & 127.8 & $7.53(1 \mathrm{H}, \mathrm{m})$ & 127.8 \\
\hline 11 & 7.66 & 130.6 & $7.60(1 \mathrm{H}, \mathrm{m})$ & 130.8 & $7.62(1 \mathrm{H}, \mathrm{m})$ & 130.7 \\
\hline 12 & - & 123.4 & - & 124.2 & - & 124.4 \\
\hline 13 & - & 155.0 & - & 155.5 & - & 155.8 \\
\hline 14 & 4.67 & 42.2 & $4.51(2 \mathrm{H}, \mathrm{s})$ & 43.1 & $4.98(2 \mathrm{H}, \mathrm{s})$ & 44.5 \\
\hline 15 & - & 185.7 & - & 184.6 & - & 186.1 \\
\hline 16 & - & 75.8 & - & 76.8 & - & 76.2 \\
\hline 17 & - & 161.1 & - & 156.2 & - & 155.5 \\
\hline 18,21 & $\begin{array}{l}1.66 \\
1.82\end{array}$ & 36.8 & $\begin{array}{l}1.66(2 \mathrm{H}, \mathrm{m}), \\
1.83(2 \mathrm{H}, \mathrm{m})\end{array}$ & 37.0 & $\begin{array}{c}1.72(2 \mathrm{H}, \mathrm{d}, J=7.83), \\
1.87,(2 \mathrm{H}, \mathrm{m})\end{array}$ & 37.2 \\
\hline 19,20 & 1.84 & 25.5 & $1.82(4 \mathrm{H}, \mathrm{m})$ & 25.5 & $1.88(4 \mathrm{H}, \mathrm{m})$ & 25.7 \\
\hline 22 & 2.29 & 27.5 & - & 148.5 & - & 152.1 \\
\hline 23 & 1.46 & 26.6 & $1.85(2 \mathrm{H}, \mathrm{m})$ & 34.2 & $\begin{array}{r}2.56(2 \mathrm{H}, \text { br t } \\
J=7.43,7.43 \mathrm{~Hz})\end{array}$ & 26.3 \\
\hline 24 & 1.25 & 21.5 & $1.20(2 \mathrm{H}, \mathrm{m})$ & 18.4 & $1.30(2 \mathrm{H}, \mathrm{m})$ & 19.1 \\
\hline 25 & 0.80 & 13.7 & $0.66(3 \mathrm{H}, \mathrm{m})$ & 13.4 & $\begin{array}{c}0.68(3 \mathrm{H}, \mathrm{t} \\
J=7.43,7.43 \mathrm{~Hz})\end{array}$ & 13.8 \\
\hline $\mathrm{NH}$ & - & - & $5.71(1 \mathrm{H}, \mathrm{s})$ & - & - & - \\
\hline $\mathrm{N}-\mathrm{OH}$ & - & - & $11.6(1 \mathrm{H}, \mathrm{s})$ & - & $12.07(1 \mathrm{H}$, br s $)$ & - \\
\hline
\end{tabular}

Notes: 1) The numbering of the carbon skeleton in irbesartan, irbesartan $E$-oxime and irbesartan Z-oxime is shown in the structures below. 2) Abbreviations: N.A., not applicable; o, overlap signals; br s, broad singlet signal.

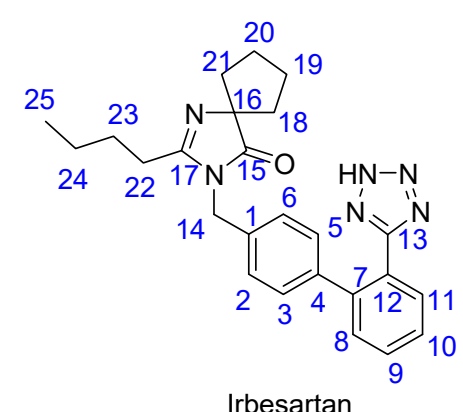

Irbesartan

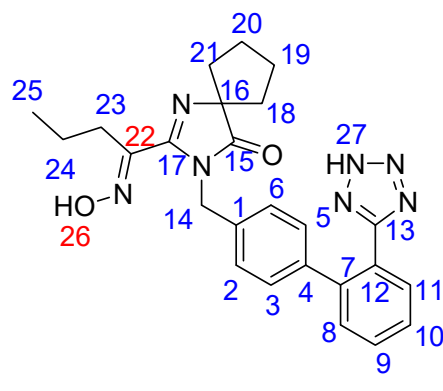

22.6 min species

Irbesartan E-oxime

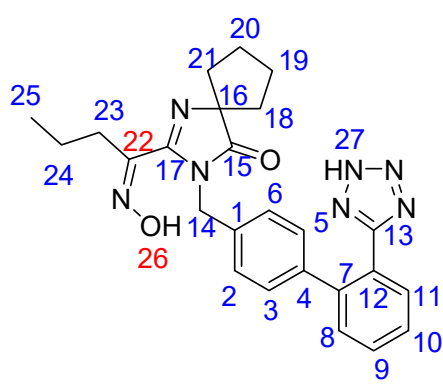

27.0 min species

Irbesartan Z-oxime 
Table 2. Distribution of irbesartan $E$-oxime and irbesartan $Z$-oxime in reactions of irbesartan with nitrous acid under various different conditions.

\begin{tabular}{|c|c|c|c|c|c|c|c|}
\hline Experiment & $\begin{array}{l}\text { Molar ratio } \\
\text { of } \mathrm{NaNO}_{2}\end{array}$ & $\begin{array}{c}\mathrm{pH} \\
\text { value }\end{array}$ & $\begin{array}{l}\text { Reaction } \\
\text { time }(\mathrm{h})\end{array}$ & $\begin{array}{c}\text { Temperature } \\
\left({ }^{\circ} \mathrm{C}\right)\end{array}$ & Solvent & $\begin{array}{c}\text { Content of } \\
\text { irbesartan } \\
\text { E-oxime (\%) }\end{array}$ & $\begin{array}{c}\text { Content of } \\
\text { irbesartan } \\
\text { Z-oxime (\%) }\end{array}$ \\
\hline 1 & $0.62 \mathrm{eq}$ & $<1.0$ & 18 & $40 \pm 2$ & NMP & 0.81 & 42.85 \\
\hline 2 & $3.1 \mathrm{eq}$ & $<1.0$ & 18 & $40 \pm 2$ & NMP & 1.68 & 76.13 \\
\hline 3 & $3.1 \mathrm{eq}$ & $<1.0$ & 6 & $10 \pm 2$ & NMP & 1.86 & 94.91 \\
\hline 4 & $3.1 \mathrm{eq}$ & $<1.0$ & 18 & $10 \pm 2$ & NMP & 2.02 & 93.66 \\
\hline 5 & $3.1 \mathrm{eq}$ & $<1.0$ & 6 & $40 \pm 2$ & $\begin{array}{c}\text { Xylene:NMP } \\
(7: 3)\end{array}$ & 0.84 & 87.92 \\
\hline 6 & $3.1 \mathrm{eq}$ & $<1.0$ & 6 & $10 \pm 2$ & $\begin{array}{c}\text { Xylene:NMP } \\
(7: 3)\end{array}$ & 0.97 & 79.89 \\
\hline 7 & $3.1 \mathrm{eq}$ & 4.0 & 6 & $40 \pm 2$ & NMP & N.D. & 14.68 \\
\hline 8 & $3.1 \mathrm{eq}$ & 4.0 & 18 & $40 \pm 2$ & NMP & 0.72 & 41.55 \\
\hline 9 & $3.1 \mathrm{eq}$ & 6.8 & 6 & $40 \pm 2$ & NMP & N.D. & 14.45 \\
\hline 10 & $3.1 \mathrm{eq}$ & 6.8 & 18 & $40 \pm 2$ & NMP & 0.65 & 39.96 \\
\hline
\end{tabular}

